\title{
Cidade adentro, cidade afora: histórias entre Associação Morungaba e PACTO-USP*
}

\section{Inside of the city, outside of the city: stories of a partnership between Associação Morungaba and "PACTO-USP"}

\author{
Maria Renata de Macedo Soares ${ }^{1}$, Eliane Dias de Castro², \\ Erika Alvarez Inforsato ${ }^{3}$
}

\begin{abstract}
SOARES, M. R. de M.; Castro, E. D. de; INFORSATO E. A. Cidade adentro, cidade afora: histórias entre Associação Morungaba e pacto-USP. Rev. Ter. Ocup. Univ. São Paulo, v. 20, n. 3, p. 193-198, set./dez. 2009.

RESUMO: A parceria entre a Associação Morungaba e o Programa Permanente Composições Artísticas e Terapia Ocupacional (PACTO) apresentada neste relato, mostra-se um território de contribuições recíprocas que amplia e complexifica o espectro de ações oferecidas a uma população de características heterogêneas, com prioridade aos que se encontram em situação de vulnerabilidade, provocada por questões de ordem econômica, clínica e/ou social. Um breve levantamento da história deste trabalho conjunto, seus projetos e desdobramentos, evidencia sua efetividade na assistência à população, na formação de estudantes de terapia ocupacional e na produção de estudos e pesquisas. Todos os envolvidos nesta parceria avançam sobre as questões do chamado terceiro setor, na medida em que se alcançam novos entendimentos, experienciando a complexidade do funcionamento social contemporâneo. Através de intervenções acompanhadas em cooperação, supervisores, coordenadores, arte-educadores e estagiários dedicam-se aos projetos que acontecem em diversos equipamentos sociais e culturais da cidade de São Paulo, desde o ano de 2000, incrementando as experiências do território de interface entre as artes, a educação e a saúde e em relação à apropriação dos espaços públicos.
\end{abstract}

DESCRITORES: Educação. Arte. Terapia ocupacional/tendências. Organizações não governamentais. Dança.

\footnotetext{
${ }^{1}$ Fonoaudióloga, Associação Morungaba.

${ }^{2}$ Docente do Curso de Terapia Ocupacional do Departamento de Fisioterapia, Fonoaudiologia e Terapia Ocupacional da FMUSP .

${ }^{3}$ Terapeuta ocupacional do Laboratório de Estudos e Pesquisa Arte e Corpo em Terapia Ocupacional da FMUSP.

Endereço para correspondência: Associação Morungaba. Rua Cristiano Viana, 977. Pinheiros. C.E.P: 05411-001. São Paulo. São Paulo. Brasil. E-mail: renata@morungaba.org.br
} 


\section{Dos começos}

E m caravana, um conjunto de carros, lotado de gente, subia por entre ruas esburacadas, becos e casas, à beira de uma estrada de trem recém-desativada. As portas de uma creche, amontoavam-se, paravam para estacionar e, ali, desciam todos: profissionais de dança, psicologia, educação, fonoaudiologia, artes, terapia ocupacional, assistência social etc.; estudantes de ensino médio ou universitário. Junto a algumas crianças iniciavase o trabalho: misto de ensino, cuidado e brincadeira, que deixava em evidência "o encontro". Encontro destes profissionais e estudantes com crianças, ávidas por contatos, fragilizadas - em situações de privação e vulnerabilidade social extrema. Encontro do qual todos saíam muito marcados uns pelos outros. (...) (INFORSATO, 2001).

O texto acima se refere ao "Projeto Descobrir" e aos acontecimentos iniciais da parceria da Associação Morungaba com o PACTO - Programa Permanente de Composições Artísticas e Terapia Ocupacional -, através do Laboratório de Estudos e Pesquisa Arte, Corpo e Terapia Ocupacional da FMUSP. A descrição destes começos evidencia a matéria de encontros sensíveis e potencializadores que constituem esta parceria há 10 anos. Este trabalho pretende fazer um relato dessa experiência.

A Associação Morungaba é uma Organização Não Governamental - ONG, sem fins lucrativos, sediada na cidade de São Paulo. Sua missão é voltada à promoção da cidadania, com estratégias de relação consigo e com seu entorno, através de atividades artísticas, educativas e lúdicas. As atividades ocorrem em locais públicos e sua ação dirige-se prioritariamente a crianças e jovens que vivem em situações de vulnerabilidade social e aos seus familiares e/ou responsáveis, bem como àqueles que trabalham ou pretendem trabalhar com estas populações, a quem, regularmente, são oferecidos cursos e estágios, contribuindo para a formação de profissionais das áreas de educação, saúde e dança/ arte-educação.

A aproximação do PACTO aos projetos da Associação Morungaba se dá pela integridade com que as propostas são realizadas, pela contundência dos processos que abarcam um grande número de crianças e jovens com necessidades evidentes de intervenção para uma maior participação social e cultural. Em geral, as parcerias, sobretudo as institucionais, têm um ciclo, se formam e se fecham. De um modo incomum esta perdura, numa ação continuada desde o ano 2000. Desta duração, resultam anos de aprendizado mútuo, no qual Morungaba e PACTO vêm enriquecendo-se a cada projeto, a cada estagiário, a cada momento conjunto. Muitas trocas próximas ocorrem com um maior deslocamento do PACTO até a sede da Associação
Morungaba para reuniões, apresentações, avaliações e contratos, numa disponibilidade recíproca, incluindo os acompanhamentos locais de cada projeto pela supervisão do PACTO, com reconhecimento e respaldo da Associação Morungaba (CASTRO et al., 2005).

Enquanto o PACTO comemora seus 10 anos de existência, a Morungaba celebra 20 anos de trajetória, primeiro através do Núcleo Morungaba que mantém suas ações na sede no bairro de Pinheiros, e a partir do ano 2000 com a fundação da Associação Morungaba, formalizando as ações sociais da instituição que se espalham por todas as regiões da cidade de São Paulo. Ao longo destes anos foram percorridos vários espaços e muitos caminhos. As primeiras ações tinham o foco no trabalho de dança com fundamento nos conceitos de Rudolf Laban, trazidos aqui para o Brasil pela professora Maria Duschenes - que realizou uma obra generosa Esta ofereceu conhecimento a muitas das pessoas que hoje trabalham no país a partir destas noções. Concluído o trabalho de campo para a pesquisa de mestrado, "Dança /Arte do Movimento para crianças Deficientes Auditivas" (NEVES, 1987), sobre como a dança pode contribuir para o desenvolvimento da criança surda, desenvolvido no início da década de 80, junto a um grupo de crianças da DERDIC - Divisão de Educação e Reabilitação dos Distúrbios da Comunicação da PUC-SP, surgiu a possibilidade de encaminhá-las ao programa de dança que a Profa. Maria Duchenes estava coordenando junto às Bibliotecas Infantis Municipais de São Paulo e acompanhar este trabalho, sendo esta uma das experiências germinais para o surgimento do Núcleo Morungaba, pois ela rompia com as paredes e os muros das instituições de tratamento e avançava no uso dos espaços públicos.

Outras experiências que foram agregadas à constituição da Associação Morungaba e que dizem respeito ao PACTO, referem-se aos projetos que se desdobraram dos movimentos de luta antimanicomial e dos movimentos pelos direitos da pessoa com deficiência. Neste contexto ocorreu, no Centro de Convivência e Cooperativa - CECCO, do Parque do Ibirapuera, o Projeto Momento Movimentado que esteve por algum tempo ligado ao trabalho desenvolvido na Fundação de Amparo e Bem Estar do Menor - FEBEM, unidade Sampaio Viana, cuja idéia era integrar as crianças que lá viviam e trazê-las aos espaços públicos.

O primeiro slogan do Morungaba era "Dança, Arte e Movimento", e posteriormente ele modificou-se para "Corpo, Arte e Convivência", estendendo os usos e sentidos dos trabalhos corporais em várias formas, empregando o movimento através da dança, dos esportes, dos jogos teatrais, da capoeira e das artes. Os projetos atuais da Associação Morungaba têm suas prioridades expandidas em relação às 
faixas etárias, acolhendo um universo populacional vasto, de crianças a idosos, estudantes de escolas públicas, usuários de equipamentos públicos governamentais ou não, e que vivem em situação de vulnerabilidade. Além disso, tem um importante acolhimento às pessoas com deficiência, e desenvolve também programas voltados a educadores e técnicos que trabalham com todas estas populações.

\section{Dos projetos}

Ao longo dos anos, a Associação Morungaba tem desenvolvido seus projetos em equipamentos públicos para dar crédito e viabilizar o direito e o interesse das populações ao aprendizado e ao exercício efetivo da noção de espaço público, bem como ao acesso às atividades e espaços culturais da cidade. Nesta abrangente trajetória da Morungaba junto a muitos parceiros, o PACTO tem tido a oportunidade de estar presente e compor com alguns dos projetos realizados, em diferentes modalidades e lugares, através de um convênio que preconiza ações de ensino, pesquisa e extensão, em que são priorizadas atividades das disciplinas de prática e estágio supervisionado, de iniciação à pesquisa, bem como de projetos de extensão com bolsas de estudo e de trabalho para estudantes do Curso de Terapia Ocupacional da FMUSP. Neste sentido, supervisores, coordenadores, estagiários e bolsistas efetuam estes deslocamentos, físicos e afetivos, importantes para a efetuação desta parceria, do qual decorrem experiências formativas relevantes que serão descritas a seguir.

A partir de um convênio entre a Associação Morungaba, a Associação Santa Cruz e o Colégio Santa Cruz, criou-se o Projeto DESCOBRIR que se desenvolveu em creches situadas numa favela do bairro Jaguaré, zona oeste de São Paulo. Primeiro na parceria com o PACTO, durante sua realização este projeto incrementava as ações desenvolvidas com as crianças de 2 a 6 anos nas três creches públicas da região, trabalhando em cada uma delas de modos diferentes. Ocorriam alguns passeios com atividades programadas que aconteciam no Parque Villa-Lobos, e em vários outros espaços públicos (bibliotecas infantis, outros parques, brinquedotecas, etc), era uma prioridade no projeto levar as crianças para esses lugares e conversar com elas sobre a importância de utilizar esses espaços, esclarecer sua propriedade coletiva. Nestas ocasiões, quando perguntados sobre: De quem é esse espaço? Em geral, eles respondiam: É do prefeito, é do guarda. Eram momentos encantadores, quando a revelação de que os espaços lhes pertenciam era feita, instantes importantes de descoberta que o projeto priorizava. As crianças saíam da favela, atravessavam a ponte e encontravam um parque público. Depois de um tempo, houve uma integração com as crianças do Colégio Santa Cruz, então, saíam cada grupo de crianças de seu bairro, com características de acessibilidade e recursos completamente diferentes para esse encontro desafiador e encontravam-se, brincavam juntas, apresentavam parte de seus mundos (músicas, jogos, lanches). Muitas atividades eram desenvolvidas no espaço da própria creche, com a oportunidade de um acompanhamento progressivo do desenvolvimento das crianças, do enfrentamento das dificuldades de convivência e de aprendizagem, criando possibilidades de deslocamento da agressividade para uma situação prazerosa e afetuosa, incentivando o uso da palavra para expressar os acontecimentos, seus desejos e suas insatisfações (INFORSATO, 2001). Uma outra ação desenvolvida neste projeto foram os trabalhos conjuntos das mães com as crianças menores (de 2 a 3 anos) com massagens e brincadeiras para favorecer o contato físico e a descontração na relação materna. Além disso, foram desenvolvidos trabalhos junto às auxiliares de desenvolvimento infantil, (as ADIs) no sentido de acolher suas angústias e contribuir para a formação de repertório de atenção e ensino das crianças através de dinâmicas corporais e rodas de conversa, onde surgiam questões relacionadas às dificuldades no trato com as crianças, o planejamento de atividades e a inserção profissional destas mulheres, em sua maioria, pertencentes àquela comunidade.

No intuito de acolher e ajudar mães adolescentes, de 13 a 18 anos, a reconhecer as necessidades de seus filhos e as suas próprias, estreitando seus laços, foi criado o Projeto MÃE + FILHO = Uma nova história - convênio entre a Associação Morungaba e a Associação Beneficente Santa Fé - Casa Vovó Ilza, abrigo destas adolescentes e de seus filhos. A grande maioria dessas mães teve uma infância com poucas oportunidades e contatos com drogas, vivendo sempre em situações de risco e morando nas ruas. Por meio das oficinas culturais - de dança, arte, música, histórias -, de registros fotográficos e de textos, essas adolescentes ganhavam autoconfiança e exercitavam a cidadania. Além dessas atividades exclusivas com as mães, foram realizados trabalhos com os filhos, buscando fortalecer a sensação de bem-estar e a integração. Para isso, eram ocupados espaços públicos de lazer e cultura, facilitando os encontros das adolescentes com pessoas de outras realidades. O programa foi mantido com o esforço e dedicação de estagiários das parcerias e colaboradores voluntários. Este projeto foi objeto de pesquisa de uma estudante do Curso de Terapia Ocupacional da FMUSP com o objetivo de contribuir para os estudos e práticas das atividades em terapia ocupacional, relacionando-as com os 
trabalhos corporais e a dança (VALENT, 2007).

A aproximação era o ponto mais delicado e investido do projeto, os profissionais envolvidos se dispuseram a adentrar o abrigo e partilhar das atividades da rotina daquelas adolescentes com seus filhos (dar banho nos bebês, assistir a novelas, estender fraldas, acompanhar a amamentação etc) até que se pudesse inscrever novas propostas, e construir uma relação fortalecida. Alguns profissionais foram convidados a oferecer oficinas com outras linguagens (dança, capoeira, fotografia, artes plásticas), e aos poucos este cotidiano pôde se enriquecer, alargando o estreito percurso que a história da vida destas adolescentes seguia, com a repetição da temática do abandono, uma vez que elas eram mães que viveram uma situação de abandono, engravidaram, foram acolhidas nesse abrigo e não conseguem interromper este ciclo, acabando com muita freqüencia, por abandonar seus filhos. O projeto buscava auxiliar que, através do cuidado da equipe com elas, pudessem cuidar de seus filhos e estabelecer uma vinculação que pudesse impeli-las a buscar outras alternativas que não a de separar-se das crianças, estabelecendo novos imaginários de si e desta relação.

Em contínuo funcionamento desde sua criação em 1991, o Projeto EstimulAÇÃO foi responsável pela institucionalização da Associação Morungaba. Em todos seus anos de existência, ele oferece oficinas gratuitas com atividades diversas (dança, capoeira, artes e histórias) e através da estimulação corporal, as ações deste projeto contribuem para o desenvolvimento da criatividade e da capacidade de estar em grupo, utilizando-se de exercícios que visam adaptação ao parceiro, respeito, confiança e solidariedade. O Projeto é dirigido às crianças de 06 a 14 anos em módulos semestrais. Com um longo histórico de parcerias e depois de passar por muitos locais, como o Centro Cultural São Paulo, bibliotecas e museus, o projeto EstimulAÇÃO mais recentemente (2004 - 2008) foi desenvolvido no Centro de Convivência e Cooperativa do Parque Ibirapuera/ SME (CECCO Ibirapuera), explorando a oportunidade de utilizar os recursos que o cenário do Parque do Ibirapuera oferece, proporcionando às crianças atividades culturais e lúdicas ao ar livre e visitas aos museus ali localizados. A presença de estagiários do PACTO se deu prioritariamente nesta fase, favorecendo intercâmbios co-extensivos com o próprio CECCO e seu funcionamento inclusivo na rede de saúde e cultura, favorecendo uma composição heterogênea dos grupos. Pioneiro das ações sociais do Morungaba, o projeto Estimulação começou como um trabalho voluntário que atendia um pequeno grupo de crianças. As parcerias e patrocínios foram fundamentais para ampliar esse atendimento, pois elas possibilitaram a contratação de professores e a expansão do número de beneficiados, entretanto, elas não se estabilizam o que faz com que o projeto assuma diferentes proporções de tempos em tempos, aumentando ou reduzindo sua capacidade de atendimento.

Responsável por uma expansão significativa na capacidade de atendimento da Associação, o Projeto SÃO PAULO É UMA ESCOLA - programa da Secretaria Municipal de Educação, é desenvolvido por várias organizações sociais parceiras, entre elas, a Associação Morungaba que o desenvolve desde sua implantação, em setembro de 2005, em diferentes regiões da cidade (Butantã, Freguesia do Ó, Guaianases e Pirituba). Diariamente o programa oferece oficinas de dança, capoeira, esportes, artes plásticas, música e teatro às crianças e adolescentes da rede municipal de ensino de SP, sob coordenação de arte - educadores, atuando na complementação do currículo escolar, promovendo acesso mais amplo à expressão artística e à participação cultural. A presença do $\mathrm{PACTO}$ neste projeto se deu de múltiplas formas através de composições diretas nas oficinas e discussões coletivas e interdisciplinares entre supervisores e estagiários de diversas profissões e arte educadores. Ao atravessar momentos de grande dificuldade com o cotidiano de uma escola pública em sua dimensão institucional rígida, todos os envolvidos são exigidos na mesma medida em que enriquecem, substancialmente. Cotidianamente, a capacidade de planejamento, realização e sobretudo de improvisação são evocadas, bem como exercícios de manejo, continência e resiliência, no intuito de compor aprendizados. Tem-se a oportunidade de conviver com a rotina da escola, seus incidentes mais ou menos graves, e suas realizações e experimentações disruptivas, e atravessar isto tudo com elementos da cultura popular, inscrevendo a todos em redes de pertencimento mais amplas. A cada semestre, estagiários universitários acompanham uma arte-educadora, trabalhando com uma linguagem específica, com grupos de diferentes faixas etárias e em diferentes momentos do processo escolar, favorecendo a participação de todas as crianças, com suas singularidades e dificuldades, incluindo-se aí as deficiências.

O Projeto USE SUA CIDADE - voltados a jovens e adultos com deficiências ou necessidades especiais - é desenvolvido pelo Núcleo Morungaba através de pequenos grupos, com estratégias de convivência e interação com espaços da cidade (museus, parques, cinemas, centros esportivos e teatros), sob coordenação do psicanalista e acompanhante terapêutico Primo Renan Nogueira de Araújo. Cada participante é convidado a efetuar pequenos exercícios de apropriação de si (seus ritmos, dificuldades e oscilações), bem como do seu entorno (variações de sensações, afetos e entendimentos possíveis, interessantes e necessários). Através do incentivo à exploração dos 
equipamentos da cultura, aos movimentos e possibilidades da cidade, ao aprendizado para o deslocamento pelas ruas e todas as implicações decorrentes (uso de transporte público, de dinheiro), e às trocas de impressões posteriores, em seu ritmo próprio e especial, os grupos enfrentam dificuldades e usufruem a convivência coletiva e os espaços da cidade, ganhando maior confiança e interesse exterior (outras pessoas e outros lugares). Semanalmente encontram-se e revezam-se entre atividades internas (jogos, dinâmicas corporais, rodas de conversas, noticias, convites, o que se quer fazer, como está a família, a cidade, os estudos, o ônibus etc) e planejamento das ações (comprar as coisas no mercado e fazer um pique-nique, cuidados na rua, pertences pessoais, documentos, horários, fôlego, cálculo de distâncias etc), e escolha das saídas para um espaço público. Nos últimos tempos, o projeto investe numa proposta arrojada, de passeios especiais noturnos numa aposta na possibilidade de autonomia e maturação de seus participantes. A parceria com o PACTO, através de estagiários e do encaminhamento de usuários, tem investido na habilitação simultânea para este conhecimento e autonomia no uso dos espaços urbanos, de modo a construir equivalências e criar redes solidárias de troca de conhecimentos. Além disso, algumas atividades não-verbais para a dinâmica dos grupos tem sido experimentadas, contribuindo com material expressivo através de brincadeiras, danças, fotos, objetos sensoriais, cozinha, jornal, internet etc, a fim de favorecer a produção e o exercício coletivo, fomentando as estratégias de circulação e exploração da cidade, bem como as trocas que daí desdobram-se, promovendo maior acessibilidade e pertinência social. Mapeiam-se territórios, buscando fazer um trabalho de constituição de redes sociais, de apropriação de circuitos significativos, disparando novos desejos de circulação extra-grupo, de conversas e andanças. No dia-adia do projeto, descobrem-se pontos de respiro da cidade no cruzamento com as exigências operativas da vida cotidiana, para que posteriormente se realizem conexões em outros espaços e tempos de suas vidas. Segundo o depoimento do coordenador Primo Araújo o grupo pode-se definir como:

um movimento em curso de duas horas e meia para tentar mudar a posição estática da vida dos participantes. E, esse trabalho na cidade é muito interessante porque ela tem calor, trânsito, ônibus, não tem lugares para sentar. E, a gente tenta privilegiar tudo que eles possam fazer: ter que pegar o telefone, ter que agendar, eles é que decidem, dá brigas, usar transporte público, metro, ônibus, a pé, calçadas enfim, é bem dinâmico...

\section{Para finalizar}

A Associação Morungaba tem muitos mais projetos com caráter semelhantes a estes que aqui foram descritos.
A seleção, como mencionado acima, refere-se àqueles dos quais o PACTO fez ou faz parte, em parceria. Diante destas apresentações, vale ressaltar que cada um desses projetos é gestado e/ou acolhido para seu desenvolvimento de modo a compor com os objetivos da Associação e de seus parceiros. E isto se dá com um trabalho que singulariza as ações e permite uma pluralidade de experimentações em artes e corpo, com o cuidado de oferecer à população-alvo atividades com qualidade e respeito. Assim, as reuniões e contratos realizados são avaliados, revistos e reiterados de tempos em tempos, constituindo uma processualidade dinâmica que busca contemplar os diversos elementos envolvidos na produção do trabalho: profissionais, supervisores, população atendida, responsáveis pelas instituições e equipamentos, comunidade adjacente, universidades, escolas etc. Este procedimento também é um aspecto que corresponde e contribui para a parceria da Associação Morungaba com o PACTO em seu compromisso com a formação de terapeutas ocupacionais no que concerne às ações na interface entre as artes e a saúde, e na possibilidade de incrementar os entendimentos das questões do terceiro setor e do funcionamento social contemporâneo que cada vez mais oferece assistência à população através da mediação de organizações não-governamentais.

Ao final de cada ano, desde sua fundação, a Associação Morungaba promove uma festa/ espetáculo em espaço externo ou teatro, aberto a um grande público, denominado "Dança Coral". Nesta ocasião, os trabalhos da Morungaba, realizados durante o ano, são expostos à apreciação de um grande público, configurando uma situação de encontro, proximidade e trocas muito intensas que, devido a sua cada vez maior abrangência de pessoas tem se configurado em outros moldes (feiras, exposições, apresentações de grupo - representantes de cada projeto, etc).

Em todos estes projetos a convergência de interesses, seja no desenvolvimento das atividades artísticas e corporais, seja no contato com populações em situação de vulnerabilidade de ordem econômica e/ou em função de deficiências, fazem da parceria PACTO - Morungaba um encontro profícuo. Campo importante para a Terapia Ocupacional, estes territórios e estas andanças solidárias entre parceiros, favorecem significativamente para a formação dos estudantes de graduação, e abrindo para as contribuições e experimentações desta área do conhecimento, relacionadas à atividade humana, às questões do cotidiano, às dinâmicas grupais, de convivência, do desenvolvimento e da cultura, bem como às de participação na vida pública da cidade, ampliando as redes de contato e de sociabilidade em suas múltiplas direções. 
SOARES, M. R. de M. et al. A. Cidade adentro, cidade afora. Rev. Ter. Ocup. Univ. São Paulo, v. 20, n. 3, p. 193-198, set./dez. 2009.

SOARES, M. R. de M.; Castro, E. D. de; INFORSATO E. A. Inside of the city, outside of the city: stories of a partnership between Associação Morungaba and "PACTO-USP". Rev. Ter. Ocup. Univ. São Paulo, v. 20, n. 3, p. 193-198, set./dez. 2009.

\begin{abstract}
The partnership between the Morungaba Association and the Permanent Program Artistic Compositions and Occupational Therapy (PACTO) presented in this report takes place in a territory of reciprocal contributions that broaden and make complex the spectrum of actions offered to a population with heterogeneous characteristics by prioritizing those who are in a situation of vulnerability triggered by economic, clinical and/or social issues. A brief assessment of the history of this joint work, its projects and developments evidences its effectiveness in the assistance to the population, in the qualification of occupational therapy students and in the production of studies and researches. Everybody involved in this partnership handles the issues of the so-called third sector inasmuch as new understandings are reached by experiencing the complexity of how things work in the contemporary social environment. Through interventions cooperatively accompanied supervisors, coordinators, art educators and interns dedicate themselves to projects that have taken place in different social and cultural pieces of equipment of the city of São Paulo since 2000, thus stimulating experiences of the territory of interface among the arts, education and healthcare and related to the appropriation of public spaces.
\end{abstract}

KEY WORDS: Education. Art. Occupational therapy/trends. Non-governmental organization. Dancing.

\title{
REFERÊNCIAS
}

CASTRO, E. D.; SAITO, C. M.; FONSECA, F. V. D. Projeto Corpo e Arte: articulando ações em Terapia Ocupacional. Relatório Científico Final. São Paulo: FAPESP, 2005.

INFORSATO, E. Aprender o mundo é construir um espaço de habitar. (Trabalho apresentado à disciplina "Clínica Winiccottiana”). São Paulo, Programa de Estudos Pós-Graduados em Psicologia Clínica - PUC-SP, 2001.

MORUNGABA. Site oficial da Associação Morungaba. Disponível em: <http://www.morungaba.org.br>. Acesso em: 17 fev. 2009.
NEVES, M. R. M. S. Dança/arte do movimento para crianças deficientes auditivas. 1987. Dissertação). Programa de Estudos Pós-Graduados em Audiologia e Distúrbios da Comunicação PUC-SP. São Paulo, 1987.

VALENT, I. U. Fazer junto com mães e bebês - Cartografia de uma experiencia sob a perspectiva dos estudos das atividades em Terapia Ocupacional. (Projeto de pesquisa apresentado à FAPESP). São Paulo, Curso de Graduação em Terapia Ocupacional da FMUSP, 2007. 